\title{
Gestão da qualidade e cultura organizacional: Um estudo de caso desenvolvido em uma fábrica de embalagens de papelão
}

\section{Quality management and organizational culture: A case study developed in a card- boards packings factory}

Gabriel Sperandio Milan

UCS Universidade de Caxias de Sul

e-mail: gabmilan@terra.com.br

Marcos Ricardo Pretto

CESF Centro de Ensino Superior Cenecista de Farroupilha

Paulo Rogério Pigozzi

CESF Centro de Ensino Superior Cenecista de Farroupilha

Recebido em 18 de junho de 2012. Aprovado em 08 de outubro de 2012

Editor Responsável: Edson Roberto Scharf, Dr.

Processo de avaliação por double blind review

\section{Resumo}

Este artigo relata o desenvolvimento de um estudo de caso sobre a evolução da qualidade no contexto de uma empresa fabricante de embalagens de papelão e sua relação com a cultura organizacional. Inicialmente, resgata-se a sistemática de implantação e a evolução do processo da qualidade na empresa. Na seqüência, as principais percepções das pessoas sobre o processo da qualidade são identificadas, destacando-se o impacto das melhorias provenientes da qualidade sobre a gestão e a cultura organizacional. Finalmente, algumas áreas de ação são propostas no sentido de maximizar os efeitos da qualidade para a empresa.

Palavras-chave: cultura organizacional, gerenciamento da qualidade total, gestão da qualidade, programas de qualidade, qualidade.

\begin{abstract}
This article tells the development of a case study on the quality evolution in the context of a corrugated cardboards packings manufacturer and its relation with the organizational culture. Initially, the implantation systematic and the evolution of the quality process are rescued in the company. In the sequence, the people main perceptions on the process of quality are identified; being distinguished the impact of the improvements proceeding from the quality on the management and the organizational culture. Finally, some areas of action are proposals in the direction to maximize the quality effect for the company.

Key words: organizational culture, total quality management, quality management, quality programs, quality.
\end{abstract}

\section{Introdução}


Com o modelo de produção em massa se tornando ultrapassado, ao final da década de 70, surgem, com as organizações japonesas, novas técnicas de gestão. Tais técnicas aliadas à crescente demanda por produtos e serviços de melhor qualidade e à mudança comportamental dos clientes, cada vez mais exigentes, percebe-se uma transformação na realidade da produção industrial. Diante disso, muitas empresas têm buscado um aperfeiçoamento constante em seus processos e atividades por meio de programas de qualidade, o que resulta em uma evolução em sua estrutura organizacional, tanto no aspecto técnico quanto em relação à sua cultura empresarial.

Neste contexto, emerge uma visão mais abrangente a respeito da qualidade, a qual direciona a empresa a adotar metodologias e práticas mais eficientes e eficazes em seus processos e, principalmente, a entender e atender às necessidades e aos desejos de seus clientes, suprindo as suas expectativas (PAVLETIC; SOKOVIC, 2009; MIGUEL; SANTIAGO, 2010; MOON et al., 2011). Assim, para satisfazer o cliente, deve-se controlar sistematicamente a qualidade, melhorá-la e inovar continuamente (KANO et al., 1984; OLIVER, 2010; PULAKANAM, 2011; KOTLER; KELLER, 2012). "Se a qualidade é relacionada a exceder continuamente as expectativas do cliente em um mercado competitivo, então, o pensamento criativo e a habilidade de inovar são competências-chave (...)" (PLESEK, 1998, p. 723).

Consequentemente, a implementação de um novo modelo de gestão da qualidade exige mudanças estruturais e comportamentais, ou seja, não é possível abordar a evolução da qualidade nas empresas sem que se faça uma relação direta com a cultura corporativa e com as mudanças organizacionais decorrentes (CROSBY, 1994; ISHIKAWA, 1993; STOCK; NAOR et al., 2008; McFADDEN; GOWEN III, 2010), até mesmo se valendo de relacionamentos interorganiza- cionais como forma de estimular as empresas em relação a processos de aprendizagem (SVENSSON; WOOD, 2005; WINKLHOFER; PRESSEY; TZOKAS, 2006), que as leve a um nível de maior competitividade em seus mercados de atuação (BARNEY; HESTERLY, 2011) e de sustentabilidade do negócio (ZINK, 2007).

Portanto, abordar a qualidade no ambiente empresarial pressupõe esforços para mudanças contínuas e permanentes. Conseguir mudar as atitudes e o comportamento das pessoas é algo fundamental. Enquanto tais atitudes e comportamentos não estiverem incorporados ao conjunto de crenças valores e princípios das pessoas, não se conseguirá consolidar uma cultura organizacional orientada para a qualidade. Por isso, a busca pela qualidade só será plena quando todos os colaboradores da empresa mudarem de mentalidade e compreenderem os seus papéis individuais a serem desempenhados e sua responsabilidade na consecução de ações e tarefas voltadas à melhoria contínua (AIDAR, 1995; FORD, 2011).

\section{Qualidade: um breve resgate concei- tual}

Feigenbaum e Feigenbaum (1999) defendem que a qualidade é um dos mais poderosos geradores de crescimento nas vendas e receitas das empresas, e um fator de sustentação da expansão dos negócios. Embora os programas, sistemas e modelos da qualidade já estejam bastante difundidos e, apesar de sua popularidade, há pouca convergência a respeito de sua definição (HUFF; FORNELL; ANDERSON, 1994; MIGUEL; SANTIAGO, 2010).

Como exemplo disso, é possível citar algumas definições de qualidade, as quais abordam diferentes enfoques. Qualidade é conformação a especificações (CROSBY, 1979), melhoria da conformação a especificações por meio da redução da incerteza e da variabilidade (DEMING, 1986), ausência de falhas ou deficiências (JURAN; GODFREY, 1999), adequação 
Gestão da qualidade e cultura organizacional: um estudo de caso desenvolvido em uma fábrica de embalagens de papelão

ao uso (JURAN, 1989), um nível de desempenho que supre as necessidades ou os desejos do consumidor provendo a sua satisfação (JURAN; GODFREY, 1999) ou, simplesmente, o julgamento do consumidor sobre a excelência global ou a superioridade de um produto e/ou de um serviço (ZEITHAML, 1988; OLIVER, 2010) em comparação às ofertas de seus concorrentes.

Neste sentido, com um direcionamento voltado ao mercado, Garvin (1987, p. 104) defende que "algumas preferências do consumidor deveriam ser tratadas como padrões absolutos de desempenho [ou de qualidade]". Consoante isso, um dos grandes desafios para a implantação e o desenvolvimento da gestão da qualidade está em integrar essas diferentes visões de qualidade nas estratégias e ações das empresas.

Para tanto, definir uma linguagem comum, que gere sinergia entre a alta administração e os colaboradores da empresa, em torno de uma mentalidade orientada para a qualidade, é o primeiro passo. No entanto, é imprescindível que a qualidade, seus procedimentos, suas ferramentas, seus critérios e seus padrões não se transformem em um fim em si mesmo, fazendo com que o objetivo primordial seja suprir as expectativas dos clientes, com um entendimento orientado ao mercado. Aliás, Freiesleben (2009) ressalta que a qualidade faz como que os profissionais das empresas aumentem o seu desempenho individual e, portanto, coletivo (relativo às equipes de trabalho), servindo como um guia evolutivo na performance das empresas.

\section{A relação entre cultura organizacio- nal e qualidade}

Diversos estudos têm abordado a relação existente entre a cultura organizacional, ou cultura corporativa, e as práticas relacionadas à gestão da qualidade e seus processos subjacentes, bem como a excelência e o desempenho organizacional (vide van der WIELE; BROWN, 2000; AM-
BROZ, 2004; DENISON; HAALAND; GOELZER, 2004; IRANI; BESKESE; LOVE, 2004; KUJALA; LILLRANK, 2004; NAOR et al., 2008; FREIESLEBEN, 2009; MIGUEL; SANTIAGO, 2010; STOCK; McFADDEN; GOWEN III, 2010; BAIRD; HU; REEVE, 2011; MOON et al., 2011, dentre outros).

Inclusive, Salegna e Fazel (1995) defendem que o sucesso proveniente da implementação de ações atinentes à qualidade depende da convergência entre o planejamento estratégico, e seus respectivos objetivos diretivos, e a cultura corporativa. Em concordância a esses autores, Ambroz (2004) salienta que os resultados advindos dos sistemas da qualidade total são equivalentes ao fortalecimento da cultura organizacional, a qual influencia, também, a performance organizacional, que pode ser traduzida por indicadores de desempenho como, por exemplo: o volume de negócios, a participação de mercado (market share), a lucratividade e a rentabilidade da empresa (IRANI; BESKESE; LOVE, 2004; TANNINEN; PUUMALAINEN; SANDSTRÖM, 2010; MOON et al., 2011). Naturalmente, isto inclui o papel fundamental dos gestores da qualidade no que diz respeito a transformar as empresas em negócios mais competitivos pela adoção de princípios, metodologias práticas e procedimentos atinentes à qualidade como um todo (PAVLETIC; SOKOVIC, 2009; ELG et al., 2011), fazendo com que todos os profissionais da empresa trabalhem a partir de um significado de suas funções e um senso de propósito empresarial mais claros e objetivos (FREIESLEBEN, 2009).

Por isso, é oportuno que se aprofunde o entendimento em torno da cultura organizacional. Ao longo da década de 80, o conceito de cultura organizacional permeou a imaginação de pesquisadores e executivos (WILSON, 1997). Nesta época, era apregoado que a chave para o sucesso das organizações era a incidência de uma cultura corporativa fortemente unificada (PETERS; WATERMAN Jr., 1982), e que 
a alta administração das organizações deveria construir e nutrir tal cultura por meio da articulação de um conjunto de valores, princípios e crenças, que deveriam ser reforçados com políticas tanto formais quanto informais, e partilhados e respeitados por todos os colaboradores, levando-os a um compromisso mais elevado (WILSON, 1997; FREIESLEBEN, 2009; FORD, 2011).

Wilson (1997) comenta, ainda, que de modo não surpreendente, a cultura corporativa se tornou rapidamente uma arma secreta para negócios bem-sucedidos. Dessa forma, com o intuito de ampliar a compreensão em torno do tema, é oportuno resgatar a definição do que seja cultura organizacional ou cultura corporativa. A cultura corporativa é um padrão de pressuposições básicas de um determinado grupo, o qual está relacionado à forma de como este grupo aprende a lidar com seus problemas de adaptação externa e de integração interna, e que tem funcionado suficientemente bem a ponto de ser considerado válido e ensinado a novos membros que sejam incorporados ao grupo como a maneira correta de perceber, pensar e agir sobre os problemas que surgirem (SCHEIN, 1991).

De acordo com Ravasi e Schultz (2006), a cultura organizacional também pode ser compreendida como um conjunto de pressuposições mentais (crenças, valores e princípios) compartilhadas que guia os gestores quanto à interpretação e à indicação de ações a partir de um comportamento adequado às situações (internas e externas) mais variadas que possam vir a surgir. Logicamente, embora uma organização de grande porte tenha a "sua cultura organizacional", podem co-existir algumas culturas conflitantes dentre as suas unidades de negócios ou áreas (setores ou departamentos) devido às diferentes características dos gestores e da forma com que lideram suas equipes de trabalho (RAVASI; SCHULTZ, 2006).
Portanto, a cultura corporativa se refere aos valores subjacentes àquilo que a organização recompensa, apóia e espera; às normas que fundamentam suas políticas, práticas e procedimentos; e ao significado que tem a incumbência de partilhar e disseminar os valores e as normas da organização (SCHNEIDER, 1988). De acordo com Plesek (2000), a cultura, os valores e princípios e a história da organização podem ser vistos, metaforicamente, como seu material genético.

Nesta direção, é possível estabelecer uma relação entre o comportamento organizacional, a gestão dos recursos humanos, as ações relativas à melhoria contínua, os processos de trabalho e as relações industriais (van der WIELE; BROWN, 2000; SVENSSON; WOOD, 2005; WINKLHOFER; PRESSEY; TZOKAS, 2006), e sua relação com aspectos tais como: ambiente interno e externo, estilo de gestão, estratégias e políticas empresariais, estrutura organizacional e processo de mudança adotado pela organização, sob uma ótica evolutiva do negócio (DALE et al. 1997a e 1997b; AMBROZ, 2004; SVENSSON; WOOD, 2005; RAVASI; SCHULTZ; 2006; FREIESLEBEN, 2009; FORD, 2011). Em um estudo realizado por Baird, Hu e Reeve (2011), há evidências empíricas de que o trabalho em equipe e o respeito às pessoas, que são aspectos atinentes à cultura de uma organização, são alguns fatores dos mais importantes no que tange a fortalecer as práticas relativas à qualidade. E isto porque um programa de qualidade resulta em profundas mudanças organizacionais, inclusive na cultura da organização, o que requer habilidades de liderança e de um diálogo aberto por parte dos gestores (BEER, 2003).

A relação entre essas variáveis, portanto, que são inter-relacionadas e que afetam direta e indiretamente a atuação e a performance das empresas, pode ser melhor entendida conforme apresentado na Figura 1. 
Gestão da qualidade e cultura organizacional: um estudo de caso desenvolvido em uma fábrica de embalagens de papelão

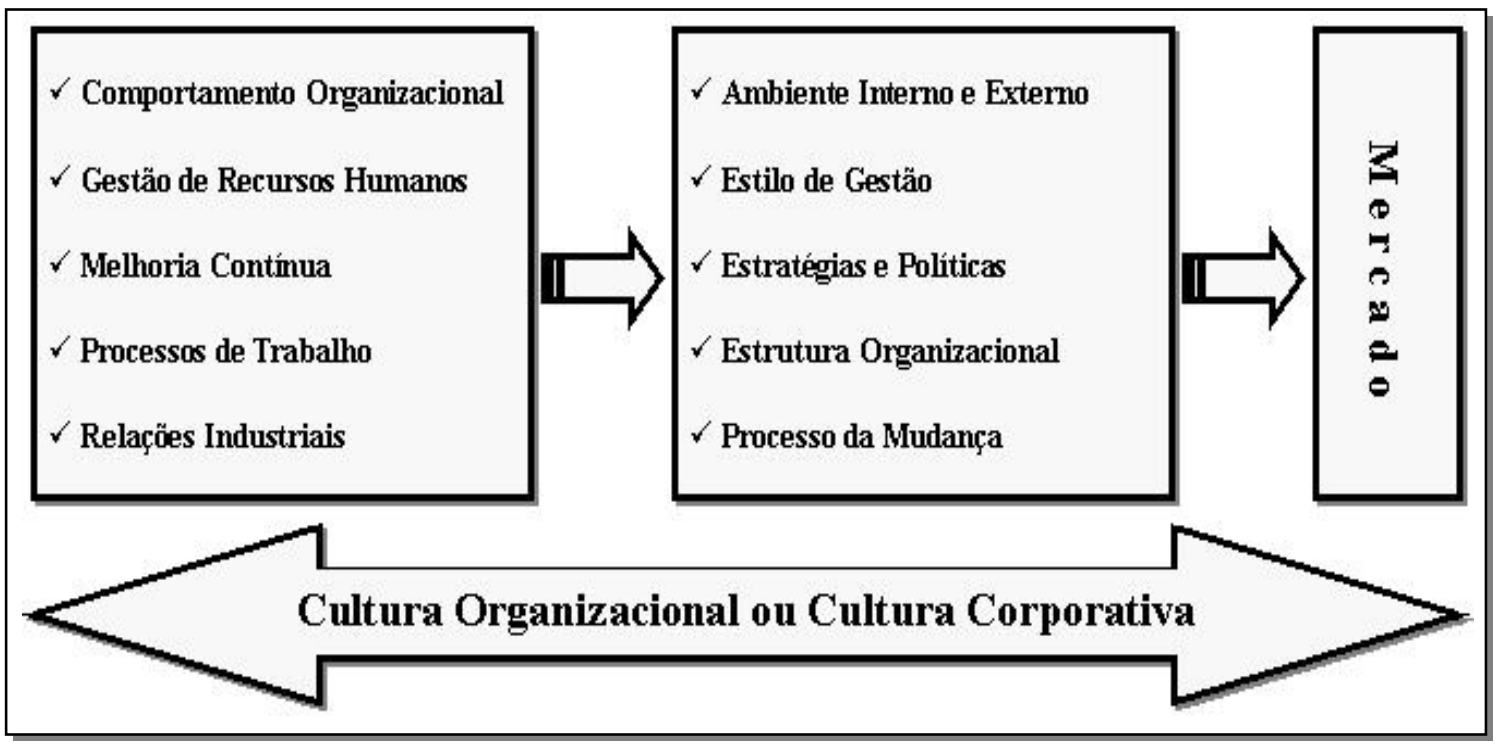

Figura 1: Cultura organizacional e a evolução do negócio

Fonte: Adaptado de van de Wiele e Brown (2000), Dale et al. (1997a; 1997b), Ambroz (2004) e Freiesleben (2009).

Neste horizonte, considerando especificamente o contexto industrial, a convergência entre os traços e as características da cultura organizacional e as práticas de gestão da qualidade são essenciais para um aumento tanto da performance operacional quanto do desempenho do negócio como um todo (BAIRD; HU; REEVE, 2011; DENISON; HAALAND; GOELZER, 2004; TANNINEN; PUUMALAINEN; SANDSTRÖM, 2010). Como ilustração disso, ao analisar o desempenho de plantas fabris em seis países diferentes, Naor et al. (2008) verificaram que a cultura organizacional apresenta forte influência sobre as práticas de gestão da qualidade e que, por sua vez, o resultado desta influência repercute positivamente no desempenho industrial.

\section{Desenvolvimento da pesquisa}

\subsection{Objetivos e método de pesquisa}

Os objetivos a que o trabalho se propõe são, respectivamente:

a) resgatar a sistemática de implantação e evolução do processo de qualidade na empresa em análise, ao longo do tempo;

b) verificar a percepção das pessoas sobre o processo da qualidade;

c) analisar o impacto das ações relativas às melhorias da qualidade sobre a gestão da empresa e sobre a cultura organizacional; e

d) propor ações que maximizem os efeitos internos e externos da qualidade.

Para que esses objetivos pudessem ser alcançados, foi utilizado o método do estudo caso (YIN, 2010), que se caracteriza como uma forma de pesquisa qualitativa, utilizada para investigar um contexto de pesquisa claramente definido (COOPER; SCHINDLER, 2011; HAIR Jr. et al., 2006).

Operacionalmente, foram utilizadas técnicas de levantamento de informações, dentre elas a análise documental (VERGARA, 2009; HENNINK; HUTTER; BAILEY, 2011), implementada pela apreciação de relatórios, manuais e outros documentos disponibilizados pela empresa. Por fim, implementou-se a técnica de entrevistas individuais, com uma abordagem semi-estruturada, e que vêm se caracteri- 
zando como um dos principais métodos de coleta de dados em pesquisas qualitativas, principalmente pelo fato do pesquisador ter a oportunidade de aprofundar o entendimento em torno do objeto de pesquisa. Embora o número de entrevistados seja pequeno, o envolvimento do pesquisador com as pessoas que detêm as informações é significativo (RIBEIRO; MILAN, 2004; KING; HORROCKS, 2010).

Outro aspecto que justifica a relevância da pesquisa qualitativa, mais especificamente da adoção das entrevistas individuais em profundidade é a crescente pluralização nos padrões de interpretação no que se refere ao contexto pesquisado. Em decorrência disso, os pesquisadores se vêem obrigados a implementar estratégias indutivas, levantando e identificando informações que possam se traduzir em "conceitos sensibilizantes" para que se construa uma abordagem de pesquisa mais consistente (FLICK, 2004; HENNINK; HUTTER; BAILEY, 2011).

De acordo com Malhotra (2006) e King e Horrocks (2010), a entrevista individual em profundidade é um tipo de entrevista pessoal em que um único respondente é arguiido por um entrevistador, que busca descobrir crenças, atitudes e informações subjacentes ao tema em estudo. Normalmente, a entrevista de caráter pessoal é escolhida quando há a necessidade de coletar uma grande quantidade de informações ou quando as informações são complexas e inter-relacionadas (AAKER; KUMAR; DAY, 2004; HAIR Jr. et al., 2010).

Sendo assim, as entrevistas individuais em profundidade, semiestruturadas, um método de coleta de dados verbais, permite que o pesquisador entenda a subjetividade intrínseca à visão dos entrevistados por meio de questões abertas, direcionadas aos objetivos de pesquisa. Neste sentido, a coleta de dados resultante das entrevistas contribui para a estruturação dos conteúdos em análise e para a identificação de elementos que auxi- liem na explanação do conhecimento implícito ao tema pesquisado (FLICK, 2004; RIBEIRO; MILAN, 2004; KING; HORROCKS, 2010).

Vale destacar que a seleção dos entrevistados compreendeu os integrantes da Comissão da Qualidade, composta pelo Gerente da Unidade, pelos Gerentes de Vendas, de Produção e Administrativo, e pelas Assessorias de Recursos Humanos, Técnica e da Qualidade, resultando em um grupo de sete pessoas que é o responsável pela implantação e desenvolvimento do processo de gestão da qualidade na empresa.

No processo de organização e de análise e interpretação dos dados, utilizouse a técnica de análise de conteúdo (BARDIN, 2004; SCHREIER, 2012), além dos pressupostos sugeridos por Wolcott (1994), Ribeiro (2000), Flick (2004), Ribeiro e Milan (2004), King e Horrocks (2010) e Hennink, Hutter e Bailey, (2011).

\subsection{Ambiência da pesquisa}

Como campo de pesquisa, foi utilizado o ambiente de uma empresa fabricante de embalagens de papelão. A empresa iniciou suas atividades industriais em 1962, na área de sacos e artefatos de papel, na cidade de Curitiba - PR. Atualmente, a empresa atua nos estados do Paraná, Santa Catarina e Rio Grande do Sul, basicamente, em três segmentos: celulose e papel, papelão ondulado e sacos e artefatos. Para ilustrar sua participação no mercado (\%) e seu desempenho frente à concorrência (colocação), segue a Tabela 1. 
Gestão da qualidade e cultura organizacional: um estudo de caso desenvolvido em uma fábrica de embalagens de papelão

Tabela 1: Participação de mercado da empresa e desempenho de mercado

\begin{tabular}{ccccccc}
\hline Segmentos de Atuação & Ano 1 (\%) & Ano 1 & Ano 2 (\%) & Ano 2 & Ano 3 (\%) & Ano 3 \\
\hline Celulose e papel & 2,60 & $8^{\text {o }}$ & 2,60 & $8^{\text {o }}$ & 2,60 & $8^{\text {o }}$ \\
\hline Papelão ondulado & 7,62 & $4^{\text {o }}$ & 8,20 & $4^{\text {o }}$ & 6,80 & $4^{\text {o }}$ \\
\hline Sacos e artefatos & 13,45 & $3^{\text {o }}$ & 15,39 & $3^{\text {o }}$ & 14,78 & $3^{\text {o }}$ \\
\hline
\end{tabular}

Obs.: Para cada ano, a primeira coluna resgata a participação de mercado da empresa, enquanto que a segunda coluna, sua colocação em relação ao mercado (concorrentes).

Com o intuito de aprofundar a análise no que diz respeito aos objetivos da pesquisa, optou-se por desenvolver o estudo especificamente em uma unidade da empresa, a qual está localizada no interior do estado do Rio Grande do Sul (RS), direcionada à fabricação de papelão ondulado. Tal unidade opera 24 horas por dia, em 3 turnos de trabalho, e conta com cerca de 670 colaboradores. Seus principais clientes estão concentrados nos seguintes segmentos: produtos alimentícios, plásticos, madeiras, mobiliário, fruticultura e floricultura, bebidas, material elétrico, papéis e papelões, vestuário, produtos químicos e derivados, metalurgia, vidros e cerâmicas e borracha.

\section{Resultados da pesquisa}

\subsection{Sistemática de implantação e evolu- ção do processo de qualidade na em- presa}

A implantação do processo de qualidade na empresa em estudo se deu, basicamente, em três grandes dimensões de análise:

\subsubsection{Sensibilização, conhecimento e conscientização para a qualidade \\ $\mathrm{Na}$ dimensão inerente à sensibili- zação, conhecimento e conscientização para a qualidade, foram verificados os se- guintes elementos:}

a) Objetivos: (i) estabelecer um processo de educação e treinamento em relação à qualidade, buscando a formação de uma base conceitual sólida para o desenvolvimento e implementação do processo da qualidade da empresa; (ii) subsidiar os participantes para que pudessem atuar como agentes de mudanças por meio de atitudes concretas, voltando-se para um sistema de gestão da qualidade total; e (iii) subsidiar os participantes para que pudessem atuar como disseminadores da cultura da qualidade aos demais colaboradores;

b) Atividades: formalização da estrutura da qualidade, definindo: o Conselho, o Comitê, a Comissão e os Coordenadores da Qualidade, além da política da qualidade e dos objetivos da qualidade para a organização;

c) Fases de implementação: $1^{\text {a }}$ Fase (1994): sensibilização, conhecimento e conscientização da Comissão; $2^{\mathrm{a}}$ Fase: (1995): dos Departamentos; $3^{\mathrm{a}}$ Fase (19961997): dos Supervisores; e $4^{a}$ Fase (19971998): do pessoal de nível operacional; e

d) Temas abordados: mudança comportamental, motivação, relação clientefornecedor interno, política da qualidade, liderança, normalização e padronização, melhoria contínua, conceito de sistema, variabilidade, auditoria da qualidade e técnica de solução de problemas.

\subsubsection{Sistematização das atividades}


Na dimensão inerente à sistematização das atividades, foram verificados os seguintes elementos:

a) Objetivo: estruturar os processos de modo a garantir a qualidade dos produtos e serviços prestados;

b) Atividades: elaboração do Manual da Qualidade (conforme NBR ISO 9001:1994), elaboração e implementação do sistema da qualidade e certificação;

c) Fases de implementação: $1^{\text {a }}$ Fase (1995): elaboração do Manual da Qualidade; $2^{\text {a }}$ Fase (1995-1999): sistematização da qualidade e treinamento básico (capacitação) em relação à sistematização da qualidade para os Departamentos e Supervisores; e $3^{\text {a }}$ Fase: (1999-2000): implantação da certificação (ISO 9001).

\subsubsection{Melhorias provenientes da quali- dade}

Na dimensão inerente às melhorias provenientes da qualidade, foram verificados os seguintes elementos:

a) Objetivos: (i) criar mecanismos que possibilitem a melhoria contínua dos processos e, consequientemente, seu acompanhamento; e (ii) implementar programa de qualificação das pessoas (sistematização, técnicas estatísticas, auditoria da qualidade e estímulo aos instrutores e multiplicadores internos dos conceitos inerentes à qualidade);

b) Fases de implementação: $1^{\text {a }}$ Fase (1995-1999): definição e implementação dos instrumentos de controle e ferramentas a serem adotadas; $2^{\text {a }}$ Fase (1999-2000): treinamento para chefias e colaboradores em nível operacional; e $3^{\text {a }}$ Fase (2000-até o momento): melhorias contínuas.

\subsection{Percepção das pessoas sobre o pro- cesso da qualidade}

Com o objetivo de compreender a percepção das pessoas em relação ao processo de implantação da qualidade na empresa e sua evolução, procedeu-se também a uma pesquisa de opinião, do tipo survey (MALHOTRA, 2006; REMLER; VAN RYZIN, 2011). O instrumento de coleta de dados (questionário) foi estruturado em quatro blocos de questões. No primeiro, os entrevistados foram questionados a respeito de seu compromisso e da sua percepção acerca do compromisso de colegas com as práticas de gestão da qualidade adotadas pela empresa. No segundo, sobre aspectos relativos ao entendimento sobre o conceito de qualidade e de suas implicações internas (na fábrica e em seus processos) e externas (para os clientes, para o mercado). No terceiro, sobre a avaliação dos processos, rotinas e "ferramentas" da qualidade. Por fim, no quarto bloco, questões sobre o perfil do respondente.

Cabe ressaltar que o questionário foi entregue aos participantes em seu local de trabalho e que foi utilizado o método do auto-preenchimento. Para as questões dos três primeiros blocos, as mesmas foram propostas em formato de "afirmativas", que deveriam ser analisadas e "respondidas" por meio de uma escala de concordância do tipo Likert de cinco pontos, tendo como alternativas 1 . discordo totalmente a 5. concordo totalmente.

A amostra contou com 82 respondentes, sendo 7 componentes do grupo diretivo, 17 Supervisores, de diversas áreas, e 58 colaboradores do nível operacional; o que representa $15,47 \%$ sobre o total de colaboradores da unidade.

Dessa forma, foram identificadas as principais percepções das pessoas:

a) há um forte compromisso das equipes de trabalho em relação à qualidade, evidenciando-se o engajamento e o suporte efetivo das chefias e um bom ambiente de trabalho (clima organizacional), havendo os recursos necessários, disponibilizados pela empresa, para a implementação das práticas de qualidade;

b) os colaboradores demonstram ser muito participativos e interessados em se 
Gestão da qualidade e cultura organizacional: um estudo de caso desenvolvido em uma fábrica de embalagens de papelão

capacitar e se aperfeiçoar em relação às mais diversas atividades intrínsecas ao programa de qualidade;

c) há um bom entendimento sobre os conceitos de qualidade e suas implicações;

d) os colaboradores entendem que há uma significativa relação entre a qualidade de vida no trabalho, as melhorias nos processos e na qualidade dos produtos e o aumento da satisfação dos clientes, o que configura um círculo virtuoso para o negócio e para os seus stakeholders (grupos de interesse); e

e) existe a necessidade do processo de melhorias contínuas da qualidade ser melhor planejado, envolvendo além da organização, como um todo, os fornecedores e os clientes.

\subsection{Impacto das melhorias da qualidade sobre a gestão e a cultura organiza- cional}

Um dos impactos da melhoria do processo da qualidade foi o desenvolvimento das chefias por meio de programas ou ações específicas de capacitação e aperfeiçoamento e de mudanças comportamentais, com base nos princípios de gestão da qualidade, focalizando conceitos filosóficos apregoados, principalmente, por autores como Deming e Ishikawa.

Tal orientação tem levado a empresa a questionar os métodos de trabalho atuais e a buscar uma sistemática mais eficaz de gestão do negócio. No entanto, oposições a mudanças também puderam ser sentidas. $O$ processo de sensibilização para a qualidade trouxe benefícios a todos os envolvidos, porém, sabe-se que se trata de um processo lento e nem sempre eficaz.

O processo de melhoria da qualidade evidencia uma tendência de maturidade do sistema de gestão, tendo provocado mudanças nos seus padrões culturais, motivados pelas influências do mercado e exigindo uma nova postura em relação aos clientes. Percebe-se, também, que para atender às expectativas dos clientes, o grupo de gestores entende que devem consoli- dar o enfoque na qualidade, direcionar a empresa para o cliente e investir sistematicamente em educação, ou seja, na capacitação e aperfeiçoamento dos colaboradores. As pessoas têm potencial e querem crescer. A qualidade é de responsabilidade de todos e a condução do processo da qualidade é responsabilidade indelegável da alta administração.

A exigência de melhorias da qualidade de produtos e/ou de serviços é algo esperado pela sociedade como um todo. Com um mercado cada vez mais competitivo, a busca da eficiência e da eficácia se faz presente em qualquer organização. Nesta direção, uma forma de buscar a competitividade é a adoção de um processo de qualidade total. É importante salientar que a empresa nunca teve como preocupação central, a certificação.

O conceito de qualidade sempre foi mais amplo. Porém, existem fatores que dificultam a implantação da qualidade total em organizações familiares, tais como conciliar os objetivos e as estratégias entre as diferentes gerações e/ou partes envolvidas na sucessão da gestão organizacional. É importante comentar que a empresa está na terceira geração na gestão do negócio.

Apesar das dificuldades para a implementação do processo da qualidade, a empresa tem dado passos significativos na melhoria de suas atividades, sendo o processo da qualidade o maior impulsionador das mudanças. Neste sentido, a estrutura organizacional na unidade foi revista com o intuito de agilizar o processo de tomada de decisões.

Existe uma sistemática de promoção interna para o aproveitamento do potencial dos colaboradores e os investimentos na qualificação dos mesmos foram intensificados. O trabalho de parceria interna tem melhorado, já que determinadas fábricas são fornecedoras de outras e está havendo a proximidade entre os gestores destas unidades, buscando uma solução conjunta para os problemas existentes. 


\subsection{Proposição de áreas de ação que ma- ximizem os efeitos da qualidade}

Recomenda-se que a empresa busque, de alguma forma, uma filosofia mais abrangente que a adotada pela escola japonesa, de maneira a deixar a empresa mais competitiva. Neste sentido, Beer e Nohria (2001) salientam que a maioria dos casos de insucesso está na pressa de mudar a empresa. Os gestores acabam se perdendo em iniciativas, perdem o foco com a quantidade de alternativas disponíveis na literatura e/ou propostas por consultores.

Ainda segundo esses autores, a empresa deve apoiar-se em duas teorias essenciais ao desempenho organizacional: a teoria com base no valor econômico e a teoria focada na capacidade organizacional. A teoria de valor econômico diz que o valor para o acionista é a única medida legítima de sucesso. Geralmente, sugere o uso de incentivos econômicos, redução do quadro funcional e reestruturação. A teoria focada na capacidade organizacional tem como foco o desenvolvimento de uma cultura corporativa e a capacitação humana pelo aprendizado individual e organizacional, assumindo um relacionamento psicologicamente forte, duradouro e baseado no comprometimento entre as partes. As empresas que efetivamente unem as abordagens, conjuntamente, podem obter melhores resultados em produtividade, lucratividade e rentabilidade. São àquelas que têm a maior probabilidade de estabelecer e consolidar uma vantagem competitiva sustentável (PORTER, 1985).

Vale destacar, então, que é imprescindível que a empresa continue investindo em programas de capacitação e aperfeiçoamento dos colaboradores, sem esquecer de qualificar o processo de recrutamento e seleção dos mesmos e pensar, de forma estratégica, em adotar um programa de remuneração complementar, com base no desempenho e no alcance de metas.

Uma outra proposta é a de buscar uma maior homogeneidade na adoção do programa de qualidade por parte de todas as unidades da empresa, fazendo com que este não fique restrito a uma única unidade de negócios. Sob este aspecto, a aceitação e o entendimento por parte da Diretoria são de fundamental importância. São os superiores hierárquicos que devem dar o exemplo, agindo e motivando os demais à adesão ao processo de qualidade total. Deve haver um compromisso inabalável com a qualidade, o qual deve começar no topo da organização, compartilhando os valores e princípios corporativos com todos os profissionais da empresa, permeando toda e qualquer iniciativa intrínseca à qualidade (KULL; NARASIMHAN; SCHROEDER, 2012; BEER, 2003).

O conceito de qualidade total está direcionado ao cliente e envolve a todos na organização. Nos dias de hoje, dizer que uma empresa está realmente comprometida com a qualidade é a mesma coisa que dizer que seus colaboradores estão orientados para os clientes. Sendo assim, o grande desafio para a melhoria da qualidade é fazer com que o cliente seja inserido no processo de melhorias contínuas da qualidade, principalmente no que diz respeito à qualidade dos produtos, dos serviços ao cliente (serviços agregados aos produtos) e do lançamento de novos produtos. Além de estreitar o relacionamento com os clientes, é oportuno que a empresa desenvolva e solidifique o relacionamento com seus fornecedores, o que pode resultar, significativamente, no nível de competitividade do negócio perante os concorrentes.

\section{Considerações finais}

As modificações que estão acontecendo no mundo dos negócios têm influenciado fortemente a gestão das empresas. As empresas enfrentam ameaças cada vez maiores nos mercados em que atuam e o desenvolvimento acelerado força a busca por novas tecnologias, além de influenciar mudanças na cultura organizacional. As empresas inseridas no contexto mercadológico, onde a qualidade era imaginada 
Gestão da qualidade e cultura organizacional: um estudo de caso desenvolvido em uma fábrica de embalagens de papelão

como uma compensação pelo preço, começam a entender que a qualidade significa preços mais competitivos com a maximização da performance de produtos e/ou serviços e da satisfação de clientes.

As mudanças no comportamento dos clientes e as relações que as empresas estabelecem entre si, justificam a necessidade de modelos mais avançados de gestão dos sistemas da qualidade. Dessa forma, emerge o Total Quality Management (TQM), o qual deve ser implantado com o objetivo de incentivar melhorias contínuas, tornando as empresas mais flexíveis, produtivas e competitivas (TANNINEN; PUUMALAINEN; SANDSTRÖM, 2010).

O mais importante é que se passe a ter uma atitude baseada na competência do próprio trabalho e do trabalho de grupo, que requer total comprometimento e envolvimento da alta administração e que deve ser estendido a todos os colaboradores, com foco no cliente, reforçando o nível de qualidade a ser entregue ao mercado.

A TQM surge como uma resposta ao atendimento às exigências de mudança que o mercado impõe. Deming (1997) afirma que para as empresas sobreviverem no mercado é necessário percorrer um caminho sistemático de práticas que conduzam mudanças em toda a organização, nas crenças e valores comportamentais, nas estratégias e nos processos de trabalho. $\mathrm{O}$ sucesso da gestão da qualidade depende e gera impacto na cultura organizacional, pois a mesma é um conjunto de maneiras tradicionais e habituais da empresa se comportar frente às situações adversas e/ou restritivas com que se defronta (MOLLER, 1999; BEER, 2003; DENISON; HAALAND; GOELZER, 2004; RAVASI; SCHULTZ, 2006; KULL; NARASIMHAN; SCHROEDER, 2012).

Portanto, para implantar e desenvolver um sistema de gestão da qualidade é necessário compreender a cultura organizacional, estabelecendo claramente os objetivos diretivos e metas a que os gestores se propõem, contando com a colaboração, cooperação e envolvimento de todos os colaboradores e, dentro do possível, inclusive, dos clientes e dos fornecedores, elevando o nível de competitividade do negócio e do desempenho organizacional (volume de negócios, participação de mercado, lucratividade e rentabilidade), melhorando o posicionamento mercadológico da empresa frente aos principais competidores (PORTER, 1985; TANNINEN; PUUMALAINEN; SANDSTRÖM, 2010; BARNEY; HESTERLY, 2011; HOOLEY; PIERCY; NICOLAUD, 2011).

Em relação ao caso estudado (empresa), como contribuições à área e a outras empresas que estejam passando por um processo evolutivo no que diz respeito à implantação e/ou consolidação de seus programas de qualidade, é possível destacar alguns aspectos. Todas as fases de implantação de um programa de qualidade são relevantes, no entanto, a primeira delas deve ser bem planejada e gradativa, não abreviando o processo de sensibilização, conhecimento e conscientização das pessoas, o qual deve estar adequado à cultura da organização, o que é defendido por Freiesleben (2009).

Outro aspecto evidenciado é o do engajamento, interesse, participação e compromisso dos profissionais, sejam em cargos de comando ou chefia sejam em cargos operacionais, em relação ao programa de qualidade da empresa, o que é fomentado por um clima organizacional saudável, pautado fortemente por melhores resultados (operacionais e do negócio) e pelo respeito aos profissionais envolvidos. E isto também encontra suporte na literatura (vide, por exemplo, (van der WIELE; BROWN, 2000; SVENSSON; WOOD, 2005; WINKLHOFER; PRESSEY; TZOKAS, 2006; BAIRD; HU; REEVE, 2011; ELG; GREMYR; HELLSTRÖM, 2011).

Além disso, até pela natureza do conceito de qualidade e por se tratar de um processo evolutivo (FREIESLEBEN, 2009), observou-se, na empresa, que tal 
processo pode ser compreendido em três grandes fases, iniciando em 1994 e culminando com a certificação pela ISO 9001 no ano de 2000. Logicamente, a adoção de práticas de gestão da qualidade e a busca por um melhor desempenho nas atividades e para a empresa não cessaram com tal certificação, ressaltando-se que, de 2000 até o momento, a empresa vem consolidando o programa de qualidade implantado e nutrindo sua cultura organizacional para princípios como o da melhoria contínua. E este processo sistemático, unindo e respeitando os aspectos atinentes à cultura organizacional e à gestão da qualidade em prol de melhores resultados é algo que outras empresas também devem perseguir (IRANI; BESKESE; LOVE, 2004; NAOR et al., 2008; BAIRD; HU; REEVE, 2011; MOON ET AL., 2011). Talvez por isso é que Kujala e Lillrank (2004) instiguem os pesquisadores e os gestores a compreenderam o processo de gestão da qualidade como um fenômeno cultural das organizações.

\section{Referências}

AAKER, D. A.; KUMAR, V.; DAY, G. S. Pesquisa de marketing. 2. ed. São Paulo: Atlas, 2004.

AIDAR, M. M. Qualidade humana: as pessoas em primeiro lugar. 2. ed. São Paulo: Maltese, 1995.

AMBROZ, M. Total quality system as a product of the empowered corporate culture. TQM Magazine, v. 16, n. 2, p. 93104, 2004.

BAIRD, K.; HU, K. J.; REEVE, R. The relationships between organizational culture, total quality management practices and operational performance. International Journal of Operations \& Production Management, v. 31, n. 7, p. 789-814, 2011.

BARDIN, L. Análise de conteúdo. 3. ed. Lisboa: Edições 70, 2004.
BARNEY, J. B.; HESTERLY, W. S. Administração estratégica e vantagem competitiva. 3. ed. São Paulo: Pearson, 2011 .

BEER, M. Why total quality management programs do not persist: the role of management quality and implications for leading a TQM transformation. Decision Sciences, v. 34, n. 4, p. 632-642, 2003.

BEER, M.; NOHRIA, N. Desenvolvendo o código da mudança. HSM Management, n. 25, p.126-132, 2001.

COOPER, D. R.; SCHINDLER, P. S. Métodos de pesquisa em administração. 10. ed. Porto Alegre: Bookman, 2011.

CROSBY, P. B. Quality is free: the art of making quality certain. New York: New American Library, 1979.

CROSBY, P. B. Qualidade é investimento. Rio de Janeiro: José Olympio, 1994.

DALE, B. G.; BOADEN, R. J.; WILCOX, M.; McQUARTER, R. E. TQM sustaining audit tool: description and use. Total Quality Management Journal, v. 8, n. 6, p. 395-408, 1997a.

DALE, B. G.; BOADEN, R. J.; WILCOX, M.; McQUARTER, R. E. Sustaining total quality management: what are the key issues? Total Quality Management Journal, v. 9, n. 5, p. 372-380, 1997b.

DEMING, W. E. Out of the crisis. Cambridge: MIT Center for Advanced Engineering Study, 1986.

DEMING, W. E. A nova economia para a indústria e a educação. Rio de Janeiro: Qualitymark, 1997.

DENISON, D. R.; HAALAND, S.; GOELZER, P. Corporate culture and organizational effectiveness: is Asia different from the rest of the world? Organizational Dynamics, v. 33, n. 1, p. 98-109, 2004.

ELG, M.; GREMYR, I.; HELLSTRÖM, A.; WITELL, L. The role of quality managers in contemporary organizations. Total 
Gestão da qualidade e cultura organizacional: um estudo de caso desenvolvido em uma fábrica de embalagens de papelão

Quality Management \& Business Excellence, v. 22, n. 8, p. 795-806, 2011.

FEIGENBAUM, A. V.; FEIGENBAUM, D. S. New quality for the $21^{\text {st }}$ century. Quality Progress, v. 32, n. 12, p. 27-31, 1999.

FLICK, U. Uma introdução à pesquisa qualitativa. 2. ed. Porto Alegre: Bookman, 2004.

FORD, M. W. Customized complliance: exploring patterns of quality adoption in a multidivisional context. Quality Management Journal, v. 18, n. 3, p. 21-32, 2011.

FREIESLEBEN, J. The quest for quality as guided evolution. Total Quality Management \& Business Excellence, v. 20, n. 11, p. 1.263-1.271, 2009.

GARVIN, D. A. Competing on the eight dimensions of quality. Harvard Business Review, v. 65, n. 6, p. 101-110, 1987.

HAIR Jr., JOSEPH, F.; BABIN, B.; MONEY, A. H.; SAMOUEL, P. Fundamentos de métodos de pesquisa em administração. Reimpressão. Porto Alegre: Bookman, 2006.

HAIR Jr., JOSEPH, F.; WOLFINBARGER, M.; ORTINAU, D. J.; BUSH, R. P. Fundamentos de pesquisa de marketing. Porto Alegre: Bookman, 2010.

HENNINK, M.; HUTTER, I.; BAILEY, A. Qualitative research methods. Thousand Oaks: Sage Publications, 2011.

HOOLEY, G. J.; PIERCY, N. F.; NICOLAUD, B. Estratégia de marketing e posicionamento competitivo. 4. ed. São Paulo: Pearson, 2011.

HUFF, L.; FORNELL, C.; ANDERSON, E. W. Quality and productivity: contradictory and complementary. Working Paper, NQRC (National Quality Research Center): The University of Michigan, 1994.

IRANI, Z.; BESKESE A.; LOVE, P. E. D. Total quality management and corporate culture: constructs of organisational excellence. Technovation, v. 24 , n. 8 , p. 643650, 2004.

ISHIKAWA, K. Controle da qualidade total: à maneira japonesa. Rio de Janeiro: Campus, 1993.

JURAN, J. M. Juran on leadership for quality. New York: Free Press, 1989.

JURAN, J. M.; GODFREY, A. Blanton. Juran's quality handbook. $5^{\text {th }}$ edition. New York: McGraw-Hill, 1999.

KANO, N.; SERAKU, N.; TAKAHASHI, F.; TSUJI, S. Attractive quality and mustbe quality. Quality, v. 14, n. 2, p. 39-49, 1984.

KING, N.; HORROCKS, C. Interviews in qualitative research. Thousand Oaks: Sage Publications, 2010.

KOTLER, P.; KELLER, K. L. Administração de marketing. 14. ed. São Paulo: Pearson, 2012.

KUJALA, J.; LILLRANK, P. Total quality management as a cultural phenomenon. Quality Management Journal, v. 11, n. 4, p. 43-55, 2004.

KULL, T. J.; NARASIMHAN, R.; SCHROEDER, R. Sustaining the benefits of a quality initiative through cooperative values: a longitudinal study. Decision Sciences, v. 43, n. 4, p. 553-588, 2012.

MALHOTRA, N. K. Marketing research: an applied orientation. $5^{\text {th }}$ edition. New Jersey: Prentice Hall, 2006.

Miguel, B. C.; SANTIAGO, G. B. Application of the total quality management approach in a Spanish retailer: the case of Mercadona. Total Quality Management, v. 21, n. 12 , p. 1.365-1381, 2010.

MOLLER, C. O lado humano da qualidade: maximizando a qualidade de produtos e serviços através do desenvolvimento das pessoas. 12. ed. São Paulo: Pioneira, 1999. 
MOON, J.; LEE, S.; YONG-SEUNG, P.; SUH, Y. A study on the causal relationships in the Korean National Quality Award model. Total Quality Management \& Business Excellence, v. 22, n. 7, 2011 .

NAOR, M.; GOLDSTEIN, S. M.; LINDERMAN, K. W.; SCHROEDER, R. G. The role of culture as driver of quality management and performance: infrastructure versus core quality practices. Decision Sciences, v. 39, n. 4, p. 671-702, 2008.

OLIVER, R. L. Satisfaction: a behavioral perspective on the consumer. New York: M. E. Sharpe, 2010.

PAVLETIC, D.; SOKOVIC, M. Quality improvement model at the manufacturing process preparation level. International Journal for Quality Research, v. 3, n. 4, p. 309-315, 2009.

PETERS, T. J.; WATERMAN Jr., ROBERT, H. In search for excellence: lessons from America's best-run companies. New York: Harper \& Row, 1982.

PORTER, M. E. Competitive advantage. New York: The Free Press, 1985.

PLSEK, P. Surprising quality: creative customer needs analysis. In: ANNUAL QUALITY CONGRESS, 52., ASQC, Philadelphia, p. 716-724, 1998.

PLSEK, P. Complexity and quality: new models for the new century. In: ANNUAL QUALITY CONGRESS, 54., ASQC, Indianapolis, p.150-157, 2000.

PULAKANAM, V. Responsibility for product quality problems in sequential manufacturing: a case study from the meat industry. Quality Management Journal, v. 18, n. 1, p. 7-22, 2011.

RAVASI, D.; SCHULTZ, M. Responding to organizational identity threats: exploring the role of organizational culture. Academy of Management Journal, v. 49, n. 3, p.433-458, 2006.
REMLER, D. K.; VAN RYZIN, G. G. Research methods in practice: strategies for description and causation. Thousand Oaks: Sage Publications, 2011.

RIBEIRO, J. L. D. Trabalhando com dados qualitativos: introdução e pesquisa de opinião. Notas de Aula. Escola de Engenharia, Programa de Pós Graduação em Engenharia de Produção, Universidade Federal do Rio Grande do Sul, 2000.

RIBEIRO, J. L. D; MILAN, G. S. Planejando e conduzindo entrevistas individuais. In: RIBEIRO, José Luis Duarte; MILAN, Gabriel Sperandio. (eds.). Entrevistas individuais: teoria e aplicações. Porto Alegre: FEEng/UFRGS, 2004. cap. 1, p. 9-22.

SALEGNA, G.; FAZEL, F. An integrative framework for developing and evaluating a TQM implementation plan. Quality Management Journal, v. 3, n. 1, p. 73-84, 1995.

SCHEIN, E. H. Organizational culture and leadership. $2^{\text {nd }}$ edition. San Francisco: Jossey-Bass, 2004.

SCHNEIDER, B. Notes on climate and culture. In: LOVELOCK, Christopher H. (ed.). Managing services. New York: Prentice Hall, 1988.

SCHREIER, M. Qualitative content analysis in practice. London: Sage Publications, 2012.

STOCK, G.; McFADDEN, K.; GOWEN III, C. Organizational culture, knowledge management, and patient safety in U.S. hospitals. Quality Management Journal, v. 17, n. 2, p. 7-22, 2010.

SVENSSON, G.; WOOD, G. Business ethics in TQM: the qualities and spectrum zones of a case illustration. The TQM Magazine, v. 17, n. 1, p. 19-34, 2005.

TANNINEN, K.; PUUMALAINEN, K.; SANDSTRÖM, J. The power of TQM: analysis of its effects on profitability, productivity and customer satisfaction. 
Gestão da qualidade e cultura organizacional: um estudo de caso desenvolvido em uma fábrica de embalagens de papelão

Total Quality Management \& Business Excellence, v. 21, n. 2, p. 171-184, 2010.

van der WIELE, Ton; BROWN, Alan. Continuously struggling with TQM. In: Annual quality congress, 54., ASQC, Indianapolis, p. 777-783, 2000.

VERGARA, S. C. Projetos e relatórios de pesquisa em administração. 11. ed. São Paulo: Atlas, 2009.

YIN, R. K. Estudo de caso: planejamento e métodos. 4. ed. Porto Alegre: Bookman, 2010.

WILSON, A. M. The nature of corporate culture service within a service delivery environment. International Journal of Service Industry Management, v. 8, n. 1, p. 87-102, 1997.

WINKLHOFER, H.; PRESSEY, A.; TZOKAS, N. A cultural perspective of relationship orientation: using organizational culture to support a supply relationship orientation. Journal of Marketing Management, v. 22, n. 1, p. 169-194, 2006.

WOLCOTT, H. F. Transforming qualitative data: description, analysis, and interpretation. Thousand Oaks: Sage Publications, 1994.

ZEITHAML, V. A. Consumer perceptions of price, quality, and value: a means-end model of synthesis of evidence. Journal of Marketing, v. 52, n. 3, p. 2-22, 1988.

ZINK, K. J. From total quality management to corporate sustainability based on a stakeholder management. Journal of Management History, v. 13, n. 4, p. 394401, 2007. 